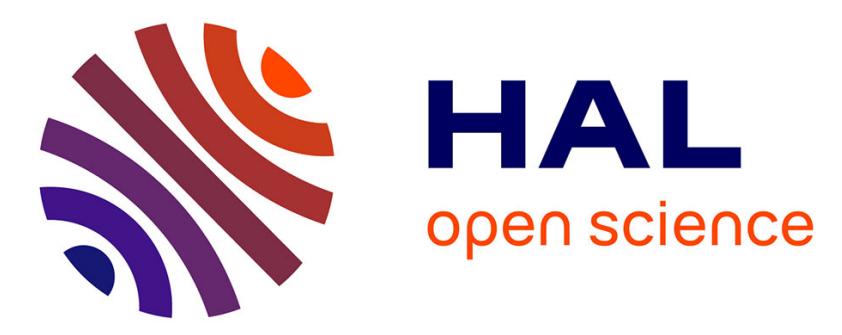

\title{
Iodine Transfer Copolymerization of Vinylidene Fluoride and a-Trifluoromethacrylic Acid in Emulsion Process Without Any Surfactants
}

Cyrille Boyer, Bruno Ameduri

\section{To cite this version:}

Cyrille Boyer, Bruno Ameduri. Iodine Transfer Copolymerization of Vinylidene Fluoride and aTrifluoromethacrylic Acid in Emulsion Process Without Any Surfactants. Journal of Polymer Science Part A: Polymer Chemistry, 2009, 47, pp.4710-4722. 10.1002/pola.23525 . hal-00393025

\section{HAL Id: hal-00393025 \\ https://hal.science/hal-00393025}

Submitted on 9 Jun 2009

HAL is a multi-disciplinary open access archive for the deposit and dissemination of scientific research documents, whether they are published or not. The documents may come from teaching and research institutions in France or abroad, or from public or private research centers.
L'archive ouverte pluridisciplinaire HAL, est destinée au dépôt et à la diffusion de documents scientifiques de niveau recherche, publiés ou non, émanant des établissements d'enseignement et de recherche français ou étrangers, des laboratoires publics ou privés. 
Iodine Transfer Copolymerization of Vinylidene Fluoride and $\alpha$ Trifluoromethacrylic acid in Emulsion process without any surfactants

$$
\text { Cyrille Boyer }^{\mathrm{a}} \text { and Bruno Améduri }{ }^{\mathrm{b}}
$$

${ }^{a}$ Current address: Centre for Advanced Macromolecular Design (CAMD), School of Chemical Sciences and Engineering, The University of New South Wales, Sydney, NSW 2052, Australia.

${ }^{\mathrm{b}}$ Ingénierie et Architecture Macromoléculaire, Institut Charles Gerhardt, Ecole Nationale Supérieure de Chimie de Montpellier (UMR 5253-CNRS), 8, rue de l'Ecole Normale, 34296 Montpellier Cedex 1 (France)

"To whom correspondence should be addressed; telephone: +33-467-144-368; Fax: Tel. +33-467-147-220; email: Bruno.ameduri@enscm.fr 
Iodine Transfer Copolymerization of Vinylidene Fluoride and $\alpha$ Trifluoromethacrylic acid in Emulsion process without any surfactants

\author{
Cyrille Boyer ${ }^{\mathrm{a}}$ and Bruno Améduri ${ }^{\mathrm{b}}$
}

${ }^{\text {a}}$ Current address: Centre for Advanced Macromolecular Design (CAMD), School of Chemical Sciences and Engineering, The University of New South Wales, Sydney, NSW 2052, Australia.

${ }^{\mathrm{b}}$ Ingénierie et Architecture Macromoléculaire, Institut Charles Gerhardt, Ecole Nationale Supérieure de Chimie de Montpellier (UMR 5253-CNRS), 8, rue de l'Ecole Normale, 34296 Montpellier Cedex 1 (France)

\begin{abstract}
The synthesis of poly(VDF-co-TFMA) copolymers (where VDF and TFMA stand for vinylidene fluoride and $\alpha$-trifluoromethacrylic acid, respectively) by iodine transfer polymerization without any surfactant is presented. First, the synthesis and the control of the copolymerization of VDF and TFMA were investigated in the presence of two chain transfer agents, 1-perfluorohexhyl iodide $\left(\mathrm{C}_{6} \mathrm{~F}_{13} \mathrm{I}\right)$ and 1,4-diodoperfluorobuane $\left(\mathrm{IC}_{4} \mathrm{~F}_{8} \mathrm{I}\right)$. TFMA monomer was incorporated in the copolymer in good yields. Moreover, the molecular weights of the resulting poly(VDF-co-TFMA) copolymers were in good agreement with the theoretical values for feed of TFMA / VDF ratios that ranged from 50/50 mol- $\%$ to $0 / 100$ mol.\%, showing that TFMA does not disturb the controlled radical polymerization of VDF. The microstructures of the produced copolymers were characterized by ${ }^{1} \mathrm{H}$ and ${ }^{19} \mathrm{~F}$ NMR to assess the amounts of each co-monomer, and the molecular weights and the end-groups of the copolymers. The results on the control of the copolymerization were compared to those obtained with and without the presences of TFMA and surfactant. The addition of a low amount of TFMA improved the control of the polymerization of VDF without using any surfactant. Also, the size of particles, assessed by light scattering, was smaller than $200 \mathrm{~nm}$. The addition of TFMA in low proportions, i.e. 5 to $10 \mathrm{~mol} \%$, enabled us to stabilize the particle size and to decrease the size by one order of magnitude. The Emulsifying behaviour of TFMA (in low amount in the copolymer, i.e. $<10 \mathrm{~mol}$ \%) were similar to those achieved
\end{abstract}


when a surfactant was added. Indeed, neither sedimentation nor destabilisation were observed after several days. The reactivity ratios for $\mathrm{r}_{\mathrm{TFMA}}$ and $\mathrm{r}_{\mathrm{VDF}}$ were 0 and 1.6 at $80{ }^{\circ} \mathrm{C}$, respectively. 


\section{Introduction}

Fluoropolymers exhibit remarkable properties, ${ }^{1-4}$ such as chemical inertness (to acids, bases, organic solvents), low dielectric constants and dissipation factors, are hydrophobicity, show excellent weathering abilities, and display interesting surface properties. Hence, these high value-added materials can find applications in many fields of high technology: aeronautics, ${ }^{5}$ microelectronics, ${ }^{6}$ optics, ${ }^{7,8}$ textile finishing, ${ }^{9,}{ }^{10}$ in the nuclear industry, ${ }^{11-13}$ in paints and coatings $^{14}$ and lithography. ${ }^{15}$ These specialty polymers can be produced by radical (co)polymerization of fluorinated monomers in organic solvent and supercritical $\mathrm{CO}_{2}{ }^{16-21}$ however they are commonly made in aqueous processes. ${ }^{1-4,11-13}$ As these halogenated monomers are highly hydrophobic, a surfactant must be added to stabilize the emulsion in monodispersed droplets of monomers. Most surfactants involved in such a process are highly also fluorinated compounds bearing a polar head, such as perfluorooctanoic acid (PFOA, $\left.\mathrm{C}_{7} \mathrm{~F}_{15} \mathrm{CO}_{2} \mathrm{H}\right)$, ammonium perfluorooctanoate $\left(\mathrm{C}_{7} \mathrm{~F}_{15} \mathrm{CO}_{2} \mathrm{NH}_{4}\right)$, perfluorooctyl sulfonic acid (PFOS $\mathrm{C}_{8} \mathrm{~F}_{17} \mathrm{SO}_{3} \mathrm{H}$ ) or sulfonate.

In recent years, such surfactants have been regarded as bioaccumulable, toxic and environmentally persistent, and severe regulations by the US Environment Protection Agency have led to a sharp decrease of their production ( $95 \%$ by 2010). Indeed by 2015 , these above surfactants will be banned. Hence, the main chemical industries producing fluoropolymers have been gathered under a consortium called the "2010/2015 PFOA Stewardship Program",22 to look for non-bioaccumulable alternatives. To the best of our knowledge, only a few fluorinated copolymers have been synthesized in aqueous systems in the absence of surfactant ${ }^{22}$. To overcome these challenges of surfactant free polymerization two objectives have been targeted: 1), the stabilization of emulsion process and 2) the incorporation of functional groups in the polymer chain.

The properties of polyvinylidene fluoride, PVDF, can also be tuned and enhanced by the presence of specific functional groups born by the backbone, i.e. adhesion, solubility, etc. To add these functional groups, one procedure currently used is the synthesis of fluoropolymers by copolymerization of fluoroalkenes with other fluorinated or non halogenated monomers. One monomer commonly used is vinylidene fluoride (VDF), because its copolymers exhibit useful properties, such as the chemical inertness, the resistance to acids and to chemical agents, piezo-, pyroelectrical, and gas-barrier properties, and low toxicity. In fact, VDF has been copolymerized with various fluorinated monomers, ${ }^{4}$ and the resulting copolymers bear functionality such as hydroxy, ${ }^{4}$, carboxylic acid ${ }^{23}$ acetoxy, ${ }^{4}$ thioacetoxy, ${ }^{4}$ sulfonyl fluoride, ${ }^{4}$ nitrile, ${ }^{4}$ bromine,${ }^{24}$ or a pentafluorosulfonyl ${ }^{25}$ group. 
An interesting way to insert a carboxylic acid function (which opens up to various further chemical modifications) arises from the copolymerization of VDF with comonomers containing such acid group. Actually, acrylic acid (AA) is too reactive (its propagation rate, $k_{\mathrm{p}}$, is very high compared to that of VDF) to lead to satisfactory poly(VDF-co-AA) copolymers, but $\alpha$-trifluoromethacrylic acid (TFMA) has already evidenced an appropriate reactivity with $\mathrm{VDF}^{23,}{ }^{26}$ In addition, the free radical terpolymerization of $\alpha$ trifluoromethacrylic acid (TFMA) with VDF and hexafluoropropylene ${ }^{23}$ was successfully carried out in organic solvent while TFMA radical homopolymerization failed. ${ }^{27,}{ }^{28}$ These reactions were carried out in solution and the present challenge deals with an emulsion process without any surfactant, under controlled radical polymerization in aqueous medium. Iodine transfer polymerization (ITP) ${ }^{29}$ has been chosen since this is a suitable technique able to control the polymerization of fluorinated olefins. Indeed, neither atom transfer radical polymerization (ATRP) ${ }^{30-33}$ nor nitroxide mediated polymerization (NMP) ${ }^{33,34}$, nor reversible addition fragmentation transfer (RAFT) ${ }^{33,35-38}$ of fluoroolefins has been reported in the literature. Interestingly, Fiering et al. ${ }^{39}$ used ATRP to copolymerize hexafluoropropene and styrene using perfluoroalkylsulfonyl chlorides and bromides, as initiator and $\mathrm{CuCl}$ as the catalyst. However, the living character was not claimed and demonstrated. Nevertheless, ITP (also called degenerative transfer) enables controlling the polymerization of different monomers, i.e. acrylic, ${ }^{40-53}$ methacrylic, ${ }^{54,55}$ styrenic, ${ }^{40,56,57}$ vinyl chloride, ${ }^{42,44,45,47,48,53,58-}$ 65 and also, fluorinated olefins. ${ }^{25,66-68}$ The synthesis of different commercially available products such as thermoplastic elastomers (TPEs) pioneered by the Daikin Company in $1979^{69}$ (which nowadays produces Daiel ${ }^{\circledR}$ TPE), ${ }^{70}$ then studied by DuPont (now Dupont Performance Elastomers) ${ }^{71-73}$ and developed later by Ausimont (now Solvay Solexis) under the Tecnoflon ${ }^{\circledR}$ trade name ${ }^{74-76}$ have been reported. In addition, the presence of the iodine end-atom potentially enables chemical modification to prepare functional polymers. Hence, the objectives of this research concern the preparation of stable emulsions of fluorinated copolymers based on VDF and TFMA without using any surfactants. 


\section{Experimental part}

\section{Materials}

Vinylidene fluoride (or 1,1-difluoroethylene,VDF, b.p. $=-82{ }^{\circ} \mathrm{C}$ ) and $\alpha$-trifluoromethacrylic acid (TFMA) were kindly offered by Solvay S.A. (Tavaux, France and Brussels, Belgium) and Tosoh F-Tech Company (Shunan, Japan), respectively. 1-Iodoperfluorohexane or perfluorohexyliodide (purity $99 \%$ ) was generously supplied by Atofina (now Arkema, PierreBenite, France). It was worked up with sodium thiosulfate and then distilled prior to use, just like 1,4-diiodoperfluorobutane. $\mathrm{Na}_{2} \mathrm{~S}_{2} \mathrm{O}_{8}$ (purity $99 \%$ ) were purchased from Aldrich. Acetonitrile, dimethylformamide (DMF), tetrahydrofurane (THF), methanol, methylethylketone and dimethylacetamide (DMAc) of analytical grade were purchased from Aldrich Chimie, 38299 Saint Quentin-Fallavier, France. They were used as supplied.

\section{Analyses}

The compositions and the structures of the oligomers obtained by ITP were determined by ${ }^{19} \mathrm{~F}$ and ${ }^{1} \mathrm{H}$ NMR spectroscopies. The NMR spectra were recorded on Bruker AC 250 or 400 (250 or $400 \mathrm{MHz}$ ) instruments, using deuterated acetone, dimethylsulfoxide (DMSO) or dimethylformamide (DMF) as the solvents and tetramethylsilane (TMS) (or $\mathrm{CFCl}_{3}$ ) as the references for ${ }^{1} \mathrm{H}$ (or ${ }^{19} \mathrm{~F}$ ) nuclei. Coupling constants and chemical shifts are given in $\mathrm{Hz}$ and ppm, respectively. The experimental conditions for ${ }^{1} \mathrm{H}$ (or ${ }^{19} \mathrm{~F}$ ) NMR spectra were the following: flip angle $90^{\circ}$ (or $30^{\circ}$ ), acquisition time $4.5 \mathrm{~s}$ (or $0.7 \mathrm{~s}$ ), pulse delay $2 \mathrm{~s}$ (or $5 \mathrm{~s}$ ), number of scans 16 (or 64), and a pulse width of $5 \mu \mathrm{s}$ for ${ }^{19} \mathrm{~F} \mathrm{NMR}$.

Size Exclusion Chromatography (SEC) analyses were performed with a SpectraPhysics apparatus equipped with two PLgel $5 \mu \mathrm{m}$ Mixed-C columns from Polymer Laboratories and a Spectra Physics SP8430 Refractive Index (RI) detector (the signals assigned to PVDF-Is gave negative values. Dimethylformamide (DMF) containing $1.5 \mathrm{wt} . \%$ $\mathrm{LiCl}$ was chosen as the eluent at $T=70{ }^{\circ} \mathrm{C}$, with a flow rate of $0.8 \mathrm{~mL} \mathrm{~min}{ }^{-1}$. Monodisperse standards were poly(styrene) (PS), purchased from Polymer Laboratories.

Assessement of the sizes of particles was achieved by light scattering using Nanotrac $®$ NPA 250 device (Microtrac Inc.). The light dispersed by the particles induced a Doppler effect, due to Brownian motion, where the signal was amplified, filtered, and mathematically treated by the Microtrac ${ }^{\circledR}$ Windows Software to generate a size distribution. 


\section{Reaction in autoclave}

Iodine transfer polymerizations of VDF and TFMA were carried out in the presence of perfluorohexyl iodide or 1,4-diiodoperfluorobutane as the CTAs and initiated by $\mathrm{Na}_{2} \mathrm{~S}_{2} \mathrm{O}_{8}$ at $75^{\circ} \mathrm{C}$ or at $80^{\circ} \mathrm{C}$.

A 160-mL Hastelloy (HC-276) autoclave, equipped with inlet and outlet valves, a manometer and a rupture disc, was degassed and pressurized with 30 bar of nitrogen to check eventual leaks. Then, a $20 \mathrm{~mm} \mathrm{Hg}$ vacuum was operated for $30 \mathrm{~min}$. Under vacuum, were transferred into the autoclave $0.230 \mathrm{~g}(0.001 \mathrm{~mol})$ of $\mathrm{Na}_{2} \mathrm{~S}_{2} \mathrm{O}_{8}, 3.0 \mathrm{~g}(0.0067 \mathrm{~mol})$ of perfluorohexyl iodide $\left(\mathrm{C}_{6} \mathrm{~F}_{13} \mathrm{I}\right)$ and $80.0 \mathrm{~g}$ of deionized water. Then, by double weighing, $10.0 \mathrm{~g}(0.10 \mathrm{~mol})$ of VDF and $2.0 \mathrm{~g}(0.013 \mathrm{~mol})$ of TFMA were introduced in the mixture. Afterwards, the autoclave was progressively heated to $80^{\circ} \mathrm{C}$, by carrying out various plateaus at $50,60,70^{\circ} \mathrm{C}$ for 2 minutes. It was observed a small exotherm of ca. $5{ }^{\circ} \mathrm{C}$ and then a sharp drop of pressure to 40 bars. After 6 hr-reaction, the autoclave was placed in an ice bath for about 60 minutes and $4 \mathrm{~g}$ of unreacted VDF was progressively released (yield 90\%). After opening the autoclave, about $100 \mathrm{~g}$ of latex emulsion was obtained. The water was removed by liophilization (evaporation at $-90{ }^{\circ} \mathrm{C}$ under 10 mbar to obtain to white powder) to lead to a white powder. The TFMA was eliminated by precipitation from methanol to obtain to a copolymer (yield $=75-85 \%$ ). The sample was characterized by ${ }^{19} \mathrm{~F}$ and ${ }^{1} \mathrm{H}$ NMR spectroscopy and SEC analysis.

The poly(TFMA-co-VDF) copolymers are soluble in polar solvents, such as acetone, DMF, THF, methylethyl ketone.

\section{Kinetics of iodine transfer copolymerization of VDF and of TFMA}

In the course of the copolymerization of VDF with TFMA aliquots were periodically sampled from the autoclave (by a probe) for to monitor: i) the conversions of both comonomers and the CTA, and ii) the evolution of the molar masses. The collected samples were frozen into liquid nitrogen to stop the polymerization reaction, then diluted in dimethylformamide (DMF) and were characterized by SEC and NMR. 


\section{Results and Discussion}

The radical copolymerization of vinylidene fluoride (VDF) with $\alpha$-trifluoromethacrylic acid (TFMA) was carried out in aqueous solution, initiated by $\mathrm{Na}_{2} \mathrm{~S}_{2} \mathrm{O}_{8}$ at $80^{\circ} \mathrm{C}$, to obtain a stable emulsion. Scheme 1 represents the copolymerization of VDF and TFMA in the presence of 1iodoperfluorohexane in water. The polymer chain is composed of several VDF units (or even of oligo(VDF) blocks) separated by one TFMA unit due to the non-propagation of TFMA. ${ }^{27}$, 28 In this study, two chain transfer agents were used: a monofunctional 1-iodide perfluorocompound, $\mathrm{C}_{6} \mathrm{~F}_{13} \mathrm{I}$, and a telechelic 1,4-diiodoperfluorinated derivative, $\mathrm{IC}_{4} \mathrm{~F}_{8} \mathrm{I}$.

\section{Insert Scheme 1}

At the end of the copolymerization, a part of the emulsion was set aside to assess the size of particles, while the other portion was freeze dried to remove water. These products were precipitated from methanol and characterized by ${ }^{1} \mathrm{H}$ and ${ }^{19} \mathrm{~F}$ NMR, SEC.

\section{Characterization of the microstructure of poly(VDF-co-TFMA) copolymers by NMR spectroscopy.}

Figure 1-A represents the ${ }^{19} \mathrm{~F}$ NMR spectrum of the dried poly(VDF-co-TFMA) copolymer produced from an initial $[\mathrm{VDF}]_{0} /[\mathrm{TFMA}]_{0}$ molar ratio of $85 / 15$ and in the presence of $\mathrm{C}_{6} \mathrm{~F}_{13} \mathrm{I}$ as the chain transfer agent (CTA). This spectrum shows the characteristic peak centered at $92 \mathrm{ppm}$ assigned to the difluoromethylene groups located in the head-to-tail VDF chaining (i.e., normal VDF addition, $-\mathrm{CH}_{2}-\mathrm{CF}_{2}-\mathrm{CH}_{2}-\mathrm{CF}_{2}$ ). The signals centered at $-93.8 \mathrm{ppm}$ corresponds to the difluoromethylene group of the VDF unit adjacent to a TFMA unit ${ }^{23}$ while those centered at $-113.4,-115.7 \mathrm{ppm}$ are assigned to the $\mathrm{CF}_{2}$ groups in $-\mathrm{CH}_{2}-\mathrm{CF}_{2}-\mathrm{CF}_{2}-\mathrm{CH}_{2}-$ and $-\mathrm{CH}_{2}-\mathrm{CF}_{2}-\mathrm{CF}_{2}-\mathrm{CH}_{2}-$ sequence, characteristic of the head-head addition of VDF adduct. A broad peak at $-68.1 \mathrm{ppm}$ is attributed to the fluorine atom in $-\mathrm{CF}_{3}$ group of TFMA incorporated in the copolymer, ${ }^{23}$ while the signal of monomer appears as a single signal at $65.3 \mathrm{ppm}$. The signals of CTA are confirmed by the peaks centered at $-80.0,-121.5,-122.5$, 123.0 , and $-126.0 \mathrm{ppm}$. The characteristic end-groups of the copolymers terminated by a VDF unit appear at $-40.0 \mathrm{ppm}$ and $-108.0 \mathrm{ppm}$ which are assigned to $-\mathrm{CH}_{2} \mathrm{CF}_{2} \mathrm{I}$ and $-\mathrm{CF}_{2} \mathrm{CH}_{2} \mathrm{I}$, respectively. The presence of two different end-groups was explained by the special ability of VDF to undergo the addition of a macroradical onto the $\mathrm{CH}_{2}=$ site (normal addition, major proportion (95 mol-\%), yielding head-to-tail addition), but also onto the $\mathrm{CF}_{2}=$ one (reverse addition, minor proportion ( $5 \mathrm{~mol} \%$ ), yielding head-to-head addition). The absence of signal at -40.0 ppm exhibits that no chain was terminated by a $-\mathrm{CF}_{2} \mathrm{I}$ group. It is worth noting that 
the sum of $-\mathrm{CF}_{2} \mathrm{I}$ and $-\mathrm{CH}_{2} \mathrm{I}$ (termination by a VDF unit) corresponds to total end-chains (Figure 1). This proves the absence of end-chain terminated by a TFMA unit $\left(-\mathrm{C}\left(\mathrm{CF}_{3}, \mathrm{CO}_{2} \mathrm{H}\right)\right.$ I). Both the weak stability of the C-I bond and the steric hindrance indicated at this site by the presence of both $\mathrm{CF}_{3}$ and $\mathrm{CO}_{2} \mathrm{H}$ groups may explain this hypothesis. Moreover, the absence of $-\mathrm{CF}_{2}$-I end-group for high molecular weight material was observed (Table 1). This result can also be explained by the difference of reactivity between $-\mathrm{CF}_{2} \mathrm{I}$ and $-\mathrm{CH}_{2} \mathrm{I}$ species, as noted in previous works on the ITP of VDF. ${ }^{25,67,68}$ Thus, $-\mathrm{CF}_{2} \mathrm{I}$ species is more reactive than $-\mathrm{CH}_{2} \mathrm{I}$ which explains the accumulation of $-\mathrm{CH}_{2} \mathrm{I}$ in the course of the copolymerization. In conclusion, the suggested decreasing order of reactivity is as follows: $-\mathrm{C}\left(\mathrm{CF}_{3}\right)-\mathrm{I}>-\mathrm{CF}_{2}-\mathrm{I}>-$ $\mathrm{CH}_{2}-\mathrm{I}$.

Examination of the ${ }^{19} \mathrm{~F}$ NMR spectra allow us to assess the $D P_{\mathrm{n}}$, experimental, VDF (i.e., the number of VDF units) and that of TFMA, $D P_{\mathbf{n}}$ experimental,TFMA (i.e., the number of TFMA units) in the copolymer, from equations 1 and 2.

$\mathrm{DP}_{\mathrm{n}, \mathrm{VDF}}=3 \times\left(\int \mathrm{CF}_{2}{ }^{\mathrm{at}-40.0 \mathrm{ppm}}+\int \mathrm{CF}_{2}{ }^{\mathrm{at}-92.0 \mathrm{ppm}}+\int \mathrm{CF}_{2}{ }^{\mathrm{at}-93.8 \mathrm{ppm}}+\int \mathrm{CF}_{2}{ }^{\mathrm{at}-108.0 \mathrm{ppm}}+\int \mathrm{CF}_{2}{ }^{\text {at }-113.4}\right.$ $\left.\mathrm{ppm}+\int \mathrm{CF}_{2}{ }^{\mathrm{at}-115.7 \mathrm{ppm}}\right) / 2 \times\left(\int \mathrm{CF}_{3}{ }^{\text {at }-80.0 \mathrm{ppm}}\right)$

$\mathrm{DP}_{\mathrm{n}, \mathrm{TFMA}}=\left(\int \mathrm{CF}_{3}{ }^{\text {at }-68.0 \mathrm{ppm}}\right) /\left(\int \mathrm{CF}_{3}^{\text {at }-80.0 \mathrm{ppm}}\right)$

where $\left(\int \mathrm{CF}_{\mathrm{X}}^{\text {at }}-\mathrm{i} \mathrm{ppm}\right.$ represents the integral of the signal centered at $-\mathrm{i}$ ppm assigned to $\mathrm{CF}_{\mathrm{X}}(\mathrm{x}$ $=2$ or 3 ).

Equations (1) and (2) indicate that 20.7 VDF and 2.4 TFMA units have been inserted in the poly(VDF-co-TFMA) copolymers (run \# 2, Table 1) and $\mathrm{M}_{\mathbf{n}}=2,100$.

To demonstrate the versatility of this polymerization technique, a telechelic chain transfer agent, $\mathrm{IC}_{4} \mathrm{~F}_{8} \mathrm{I}$, was also used (Figure 1B) which leads to a telechelic copolymer bearing two iodine end-groups. Figure 1B shows the ${ }^{19} \mathrm{~F}$ NMR spectrum of the copolymer obtained using a similar feed ratio of VDF and TFMA, and a similar concentration of CTA as above. The presence of CTA was confirmed by the signals at -123.2 and $-112.2 \mathrm{ppm}^{67,68}$ assigned to $-\left(\mathrm{C} \underline{F}_{2}\right)_{2}-$ and to $-\left(\mathrm{CF}_{2}\right)_{2}-\underline{C F}_{2}-\mathrm{CH}_{2}$, respectively. Also, a similar composition of VDF and TFMA was inserted in the poly(VDF-co-TFMA) copolymer chains, which means that the reactivity of both these monomers were not affected by the nature of the CTA used. However, in the case of this telechelic CTA, two end-groups were simultaneously observed, i.e. $-\mathrm{CH}_{2} \mathrm{I}$ and $-\mathrm{CF}_{2} \mathrm{I}$ in approximately the same amount. . 


\section{Insert Figure 1}

The ${ }^{1} \mathrm{H}$ NMR spectrum (Figure 2) confirms the copolymerization of TFMA by the absence of signals at 6.5 and at $6.7 \mathrm{ppm}$ assigned to the methylene group of the double bond $\left(\mathrm{C}_{2}=\right)$ of TFMA monomer. The spectrum also shows different signals centered at $2.8 \mathrm{ppm}$ and $3.3 \mathrm{ppm}$ which are attributed to $-\underline{\mathrm{C}}_{2}-$ of VDF and TFMA and to $-\underline{\mathrm{C}}_{2}-\mathrm{I}$, respectively. The absence of the triplet of triplets centered at $6.3 \mathrm{ppm}$, assigned to $\mathrm{HCF}_{2} \mathrm{CH}_{2}$, evidences that there is no observable transfer to water, to the monomers or to the copolymer itself. The peak centered at $2.5 \mathrm{ppm}$ is assigned to the tail-to-tail addition of VDF, i.e. $-\mathrm{CF}_{2}-\mathrm{C}_{2}-\mathrm{C}_{2}-\mathrm{CF}_{2}-$ which is rather small showing a tail to tail defect of $4.5 / 92.1=4.9 \mathrm{~mol} \%$, calculated by the ratio of $\mathrm{CH}_{2}$ attributed to signal at $2.5 \mathrm{ppm}$ to signal at $2.8 \mathrm{ppm}$.

\section{Insert Figure 2}

\section{Assessment of the functionality of poly(VDF-co-TFMA)-I copolymers}

The presence of end-group, such as $-\mathrm{CF}_{2} \mathrm{I}$ or $-\mathrm{CH}_{2} \mathrm{I}$, can be exploited to incorporate a range of chemical functionalities, such as alcohol, carboxylic acid, azido, ester, allylic functions ${ }^{4,29}$ or to synthesize block polymers. ${ }^{57}$ However, $-\mathrm{CH}_{2} \mathrm{I}$ end-group is less reactive ${ }^{57,68}$ and can not easily be modified to another reactive group. 4, 29, 77

Using the previous results obtained by ${ }^{19} \mathrm{~F}$ NMR, it is possible to assess the evolution of $\mathrm{CF}_{2} \mathrm{I}$ functionality versus the number of VDF units in the polymer chain. Figure 3 exhibits the evolution of the functionality in $-\mathrm{CF}_{2} \mathrm{I}$ versus the number of units of VDF. The $-\mathrm{CF}_{2} \mathrm{I}$ amount in the poly(VDF-co-TFMA) copolymer decreases with the number of VDF units inserted the polymer chains whatever the CTA used. This result was also observed in the case of the homopolymerization of VDF, ${ }^{67,68}$ in the copolymerizations of VDF with perfluoromethyl vinyl ether, ${ }^{73}$ and the terpolymerization of VDF with HFP and pentafluorosulfonyle monomers. $^{25}$

This can be explained by the inversion of VDF during the polymerization and the difference of reactivity between $-\mathrm{CH}_{2} \mathrm{I}$ and $-\mathrm{CF}_{2} \mathrm{I}$ end-groups shown by their transfer constants $(\mathrm{Ctr}=$ 7.7 and 0.3 , respectively at $75{ }^{\circ} \mathrm{C}$ ). ${ }^{68}$ The decrease of $-\mathrm{CH}_{2} \mathrm{CF}_{2} \mathrm{I}$ end-group depends on the nature of the CTA. Figure 3 shows that telechelic CTA gave a relatively more slowly decrease of the $-\mathrm{CF}_{2} \mathrm{I}$ functionality versus the number of VDF units in the polymer. This is a surprising result, explained by the fact that, in the case of the telechelic $\mathrm{CTA}$, both $\mathrm{CF}_{2} \mathrm{I}$ sites generate 
one chain. The probability to have an inversion event increases with the number of VDF as described in a previous work. ${ }^{68}$

The comparison of different polymerizations, i.e. the homopolymerization of VDF, the copolymerization of VDF and TFMA, and the terpolymerization of VDF with hexafluoropropylene and 1,1,2-trifluoro-2-pentafluorosulfanylethylene exhibits a similar trend on the evolution of $-\mathrm{CF}_{2} \mathrm{I}$ functionality versus the number of VDF units. However, the terpolymer induced a less significant decrease. Presently, the explanation is not clear, but it is possible to claim that the insertion of HFP and $\mathrm{SF}_{5}$ containing-monomers ${ }^{25}$ can limit the inversion of VDF by the electronic effect or by the steric hindrance of their $\mathrm{CF}_{3}$ and $\mathrm{SF}_{5}$ sidegroups.

\section{Assessment of the molecular weights of poly(VDF-co-TFMA)-I copolymers}

Figure 4 shows the size exclusion chromatograms (SEC) of poly(VDF-co-TFMA) copolymers for different CTA concentrations. The polydispersity indices (PDIs) are close to 1.7-1.9 and indicate the pseudocontrol of the radical polymerization. Indeed, ITP does not lead to a narrow PDI in contrast to other pseudoliving techniques, such as NMP, ATRP, or RAFT polymerization, ${ }^{38,78,79}$ and is due to a low exchange constant $\left(\mathrm{C}_{\mathrm{ex}}\right){ }^{80,81}$ To improve the exchange transfer constant, catalyst can be introduced as suggested by Fukuda et al. ${ }^{55,80,82}$ Moreover, these molecular weights, $M_{\mathrm{n}}$, and PDIs were assessed in using a polystyrene calibration, but the presence of carboxylic acid group may also induce the adsorption of this polymer on the columns and explain the difficulty to analyze these copolymers by SEC.

Table 1 summarizes several characteristics of the copolymers obtained, using a feed molar ratio $[$ TFMA] $[\mathrm{VDF}]=15 / 85(\mathrm{~mol}-\%)$. It can be noted that the composition of copolymer is quite close to that of the feed. Also, the molecular weights of the copolymers can be tuned by varying the CTA concentration. The targeted molecular weights were determined from Equation 3. Table 1 shows that these values are in good agreement with experimental ones assessed by NMR (Equations 1 and 2).

$$
M_{\mathrm{n}, \text { targeted }}=\left([\mathrm{VDF}]_{0} \times M^{i D F}+[\mathrm{TFMA}]_{0} \times M^{T F M A}\right) /\left([\mathrm{CTA}]_{0}+M^{\mathrm{CTA}}\right)
$$

Where $M^{\text {TFMA }}, M^{\text {IDF }}, M^{\mathrm{CTA}}$ stand for the molar masses of TFMA (140 g.mol ${ }^{-1}$ ), VDF $\left(64 \mathrm{~g} . \mathrm{mol}^{-1}\right)$ and of CTA (446 or 454 g. mol $\left.{ }^{-1}\right)$, respectively.

In addition, the SEC results show a good correlation with the molecular weights assessed by NMR. Moreover, a relatively low PDI was observed when the CTA was inserted in the 
medium. In addition, $\mathrm{IC}_{4} \mathrm{~F}_{8} \mathrm{I}$ gave a lower PDI (it was close to 1.4 , while for $\mathrm{C}_{6} \mathrm{~F}_{13} \mathrm{I}$ it was 1.61.9) which indicates that a better control of the polymerization was achieved.

In contrast, in the absence of TFMA and surfactant (runs \# 8 and 9), the yields of the polymerization of VDF were lower (close to $40 \mathrm{wt}-\%$ ) and a discrepancy was noted between the targeted and experimental molecular weights. To improve the control of the polymerization and the yield, perfluorooctanoic acid (PFOA) was added as the surfactant (runs \# 10 and 11 in Table 1). Finally, as a comparison, the radical copolymerization, carried out in the absence of CTA (run \# 7, Table 1) produced a high molecular weight-polymer with a broad polydispersity index $\left(\mathrm{PDI}=3.6\right.$ ), a VDF conversion of $40 \mathrm{~mol}-\%$, and $M_{\mathrm{n}}=220,000 \mathrm{~g}$ $\left.\mathrm{mol}^{-1}\right)$.

\section{Insert Table 1}

As expected, the increase of the TFMA concentration in the feed ratio favored an increase of the TFMA monomer in the copolymers. The determination of the composition of VDF and TFMA units in the copolymer was assessed from ${ }^{19} \mathrm{~F}$ NMR analysis and equation 4 after purification.

Mol-\% VDF in copolymer $=\left(\int \mathrm{CF}_{2}{ }^{\text {at }-40.0 \mathrm{ppm}}+\int \mathrm{CF}_{2}{ }^{\text {at }-92.0 \mathrm{ppm}}+\int \mathrm{CF}_{2}{ }^{\text {at }-93.8 \mathrm{ppm}}+\int \mathrm{CF}_{2}{ }^{\text {at }-108.0 \mathrm{ppm}}\right.$ $\left.+\int \mathrm{CF}_{2}{ }^{\text {at }-113.4 \mathrm{ppm}}+\int \mathrm{CF}_{2}{ }^{\mathrm{at}-115.7 \mathrm{ppm}}\right) /\left[\left(\int \mathrm{CF}_{2}{ }^{\mathrm{at}-92.0 \mathrm{ppm}}+\int \mathrm{CF}_{2}{ }^{\text {at }-113.4 \mathrm{ppm}}+\int \mathrm{CF}_{2}{ }^{\text {at }-115.7 \mathrm{ppm}}\right)+(2 \times\right.$ $\mathrm{CF}_{3}{ }^{\text {at }-68.0 \mathrm{ppm} / 3)]}$

Where $\int \mathrm{CF}_{\mathrm{x}}{ }^{\text {at }-\mathrm{i} p \mathrm{pm}}$ represents the integral of the signal centered at $-\mathrm{i}$ ppm assigned to $\mathrm{CF}_{\mathrm{x}}(\mathrm{x}$ $=2$ or 3 ).

It is observed that the compositions of the copolymers are richer in VDF than those of the feed ratio. These results reveal that the VDF reacts preferentially to the TFMA (Table 2) in the copolymerization. The increase of TFMA in the feed ratio resulted in a reduction of the yield, concomitant to an increase in the PDI (Table 2). However, it is not possible to conclude that this increase of PDI arises from a loss of control of the polymerization or from a limitation of SEC analysis mentioned above.

\section{INSERT TABLE 2}


The introduction of TFMA, even in low amount, in the course of the copolymerization allowed us to obtain a similar result to that achieved in the presence of PFOA.

\section{Insert Figure 4}

\section{Assessment of the reactivity ratios}

The compositions of poly(VDF-co-TFMA) copolymers are summarized in Table 2 for two different CTAs. No significant difference was observed for both these CTAs. The molar proportion of VDF in the copolymer was higher than that in the feed. This demonstrates that VDF is more reactive than TFMA when the copolymerization is carried out in an aqueous medium, in contrast to a previous study ${ }^{23}$ where copolymerization was achieved in an organic medium. One explanation can be that the VDF is concentrated in small droplets which are dispersed in water, while the TFMA is soluble in the water phase. This shows that the VDF concentration is artificially higher than that of TFMA at the polymerization region (i.e. within the droplet).

To confirm this observation, the kinetics of copolymerization of VDF with TFMA were examined. The reactivity ratios of both comonomers $\left(r_{1}\right.$ and $\left.r_{2}\right)$ were assessed using Jaacks' method. ${ }^{83}$ This method is very interesting in the case of one of the monomers does not homopolymerize ${ }^{84,85}$ Moreover, due to the complexicity of the reaction in autoclave and aqueous solution, it is easier to carry out. For both these reasons, we have chosen to use this method. The reactivity ratio of $\mathrm{r}_{\mathrm{VDF}}$ can be deduced by plotting $\ln \left([\mathrm{VDF}] /[\mathrm{VDF}]_{0}\right)$ versus $\ln \left([\mathrm{TFMA}] /[\mathrm{TFMA}]_{0}\right.$ ) using a high VDF concentration (Figure 5). This leads to a straight line, the slope of which gives $\mathrm{rDDF}_{\mathrm{VDF}}=1.6$ at $80^{\circ} \mathrm{C}$. Then, the radical copolymerization of TFMA with VDF involving a high excess of TFMA ( 95 mol. \%) was realized. As expected, the absence of polymer after polymerization revealed that TFMA does not homopolymerize (absence of polymer, yield inferior to $10 \%$ ) and is in agreement with Ito et al. ${ }^{27}$ and McElroy et al.' $\mathrm{s}$ results ${ }^{28}$. Thus, $\mathrm{r}_{\mathrm{TFMA}}=0$ at $80^{\circ} \mathrm{C}$ in aqueous solution. This value was similar to that assessed when the copolymerization was carried out in solution but with a different reactivity ratio value of VDF $\left(r_{\mathrm{VDF}}=0.34\right.$ at $\left.74{ }^{\circ} \mathrm{C}\right)$ showing in that case a tendency to alternation ${ }^{23}$. The $r_{\mathrm{VDF}}$ values are different from both processes, i.e. $\mathrm{r}_{\mathrm{VDF}}=0.34$ (in organic medium at $74{ }^{\circ} \mathrm{C}$ ) and 1.6 (in water at $80^{\circ} \mathrm{C}$ ), respectively.

\section{Insert Figure 5}

From both these new results, a possible mechanism of the radical copolymerization of VDF and TFMA can be suggested. The decomposition of $\mathrm{Na}_{2} \mathrm{~S}_{2} \mathrm{O}_{8}$ generates the formation of 
sulphate radicals (in the water phase) that are able to initiate the polymerization of TFMA and VDF. The presence of TFMA in higher concentration than that of VDF due to the low solubility of VDF in water promotes the insertion of TFMA in the poly(VDF) chains, until the polymer chains become too hydrophobic and thus prefer to go inside the droplet of VDF monomers to continue the polymerization. This assumption is in agreement with the satisfactory stability of such resulting emulsions

\section{Assessment of the particle size}

The incorporation of TFMA changes the chemical properties of PVDF. Indeed, at the end of the polymerization, stable emulsions were obtained. After several days, neither coagulation nor sedimentation were observed, while a reaction carried out under the same experimental conditions with VDF (i.e. without any addition of TFMA) led to a rapid sedimentation (and coagulation). The sizes of the particles of different poly(VDF-co-TFMA)-I copolymers were measured by light scattering (Figure 6). The sizes of the particles for the (poly(TFMA-coVDF) copolymer containing $2 \%$. mol with $16 \%$. mol of TFMA are close to 150 and $100 \mathrm{~nm}$, respectively and are monodispersed. These observations confirm the stabilization of poly(VDF) by the insertion of TFMA in emulsion. However, for a poly(VDF)-I obtained by the same process gave a polydispersed latex with a size of particles higher than $1000 \mathrm{~nm}$ and very. These emulsions were stable with time (it was observed neither aggregation nor decantation after three weeks).

\section{Insert Figure 6}

\section{Acknowledgements}

The authors thank the Atochem (Pierre Benite, France) Solvay S.A. (Tavaux, France and Brussels, Belgium) and Tosoh F-Tech Company (Shunan, Japan, Dr Yoshida and Kawada) for providing with $\mathrm{C}_{6} \mathrm{~F}_{13} \mathrm{I}$, and VDF and TFMA comonomers, respectively.

\section{Conclusion}

Iodine transfer copolymerization of $\alpha$-trifluoromethacrylic acid (TFMA) and vinylidene fluoride (VDF) led to copolymers in high yields in aqueous medium in the absence of any surfactants and in the presence of perfluorohexyl iodide or 1,4-diodoperfluorobutane as chain transfer agents. To the best of our knowledge, this is the first investigation which reports the radical copolymerization of TFMA and VDF in emulsion. A first part showed that VDF and 
TFMA can be polymerized by iodine transfer polymerization. Though the linear "molar masses - comonomer conversions" relationship was not given, the good agreement between the theoretical and experimental molecular weights was demonstrated and the controlled character of that copolymerization was enhanced by the narrow PDI values. Moreover, the incorporation of VDF in the copolymer was always higher than that in the initial composition. This showed that TFMA is slightly less reactive than VDF, as evidenced by their reactivity ratios, $\mathrm{r}_{\mathrm{TFMA}}=0$ and $\mathrm{r}_{\mathrm{VDF}}=1.6$, at $80{ }^{\circ} \mathrm{C}$. Interestingly, the introduction of TFMA in the emulsion of VDF allows to improve the control and the process of the polymerization without adding any surfactant, but also, to obtain a stable emulsion. Further surveys on the potential applications as fuel cell membranes, ${ }^{86}$ surfactants or paints and coatings are under progress.

\section{References}

1. Feiring, A. E., In Organofluorine Chemistry: Principles and Commercial Applications. In Banks, R. E., Smart, B. E., Tatlow, J. C., Ed. Plenum Press: New York, 1994; Vol. 15, pp $339-372$.

2. Scheirs, J., Modern Fluoropolymers. Wiley: New York, 1997.

3. Hougham, G.; Cassidy, P. E.; Johns, K.; Davidson, T., Fluoropolymers 2: Properties. Kluwer/Plenum: New York, 1999.

4. Ameduri, B.; Boutevin, B., Well-Architectured Fluoropolymers: Synthesis, Properties and Applications. Elsevier: Amsterdam, 2004.

5. Banks, B. A., In Modern Fluoropolymers. In Scheirs, J., Ed. Wiley and Sons: New York, 1999; Vol. 4, pp 103-114.

6. Pawloski, A. R. L. F., B.; Levinson, H. J.; Hirscher, S.; Schwarzl, S.; Lowack, K.; Kamm, F.-M.; Bender, M.; Domke, W.-D.; Holfeld, C.; Dersch, U.; Naulleau, P.; Letzkus, F.; Butschke, J. Proc. SPIE-Int. Soc. Opt. Eng. 2004, 5567, 762.

7. Maruno, T.; Nakamura, K. J. Appl. Polym. Sci. 1991, 42, 2141.

8. Boutevin, B.; Rousseau, A.; Sage, J.-M. (Assigned to Atofina) U.S. Patent 2004/0,976,764. 2004 
9. Boutevin, B.; Pietrasanta, Y., Les Acrylates et polyacrylates fluores. Erec: Paris, 1998.

10. Dams, R. J.; Martin, S. J. (Assigned to 3M company) U.S. Patent 2005/121,644.

11. Robinson, D.; Seiler, D. A. In Potential Applications For Kynar Flex PVDF in the muclear industry. Proceedings American Glovebox Society, National Conference, Linings, Coatings, and Materials, Seattle WA, August 16-1993; Seattle WA, August 16-1993; pp 1014.

12. Seiler, D. A., PVDF in the Chemical Process Industry. In Modern Fluoropolymers, Scheirs, J. e., Ed. Wiley: New York, 1997; pp 487-506.

13. Humphrey, J. S.; Amin-Sanayei, R., Vinylidene Fluoride Polymers. In Encyclop. Polym. Sci. Techn. 3rd ed, Mark, H. F., Ed. Wiley: New York, 2004; Vol. 4, pp 510-533.

14. Bongiovanni, R.; Malucelli, G.; Pollicino, A.; Tonelli, C.; Simeone, G.; Priola, A. Macromol. Chem. Phys. 1998, 199, 1099.

15. Brady, R. Chem. Br. 1990, 26, 427-438.

16. Dinoia, T. P.; Conway, S. E.; Lim, J. S.; McHugh, M. A. J Polym Sci, Part B: Polym Phys 2000, 38, 2832-2840.

17. Ahmed, T. S.; DeSimone, J. M.; Roberts, G. W. Macromolecules 2006, 39, 15-18.

18. Beuermann, S.; Imran-ul-haq, M. Macromol. Symp. 2007, 259, 210-217.

19. Beuermann, S.; Imran-U1-Haq, M. J Polym Sci, Part A: Polym Chem 2007, 45, 56265635.

20. Imran-ul-haq, M.; Tiersch, B.; Beuermann, S. Macromolecules 2008, 41, 7453-7462.

21. Ahmed, T. S.; DeSimone, J. M.; Roberts, G. W. Macromolecules 2009, 42, 148-155.

22. 2010/15 PFOA Stewardship Program. U.S. Environmental Protection Agency (January, 2006),

23. Souzy, R.; Ameduri, B.; Boutevin, B. Macromol Chem Phys 2004, 205, 476-485. 
24. Sauguet, L.; Boyer, C.; Ameduri, B.; Boutevin, B. Macromolecules 2006, 39, 90879101.

25. Boyer, C.; Ameduri, B.; Boutevin, B.; Dolbier, W. R.; Winter, R.; Gard, G. Macromolecules 2008, 41, 1254-1263.

26. Ameduri, B.; Boyer, C. (Assigned to Tosoh F-Tech Inc., Japan) JP. 2008/214420, 20070301., 2008

27. Ito, H.; Giese, B.; Engelbrecht, R. Macromolecules 1984, 17, 2204.

28. McElroy, K. T.; Purrington, S. T.; Bumgardner, C. L.; Burgess, J. P. J Fluorine Chem $1999,95,117$.

29. David, G.; Boyer, C.; Tonnar, J.; Ameduri, B.; Lacroix-Desmazes, P.; Boutevin, B. Chem Rev 2006, 106, 3936 -3962.

30. Matyjaszewski, K., Controlled/living radical polymerization: Progress in ATRP, NMP and RAFT. ACS Symp Ser (Am Chem Soc): 2000; Vol. 768.

31. Matyjaszewski, K.; Xia, J. Chem Rev 2001, 101, 2921-3089.

32. Tsarevsky, N. V.; Matyjaszewski, K. Chem Rev 2007, 107, 2270-99.

33. Braunecker, W. A.; Matyjaszewski, K. Prog Polym Sci 2007, 32, 93-146.

34. Hawker, C. J.; Bosman, A. W.; Harth, E. Chem Rev 2001, 101, 3661-3688

35. Moad, G.; Chong, Y. K.; Postma, A.; Rizzardo, E.; Thang, S. H. Polymer 2005, 46, 8458-8468.

36. Moad, G.; Rizzardo, E.; Thang, S. H. Aust J Chem 2005, 58, 379-410

37. Moad, G. Aust J Chem 2006, 59, 661-662.

38. Moad, G.; Rizzardo, E.; Thang, S. H. Polymer 2008, 49, 1079-1131.

39. Feiring, A. E.; Wonchoba, E. R.; Davidson, F.; Percec, V.; Barboiu, B. J Polym Sci, Part A: Polym Chem 2000, 38, 3313-3335.

40. Gaynor, S. G.; Wang, J.-S.; Matyjaszewski, K. Macromolecules 1995, 28, 8051-6. 
41. Farcet, C.; Lansalot, M.; Pirri, R.; Vairon, J. P.; Charleux, B. Macromol. Rapid Commun. 2000, 21, 921-926.

42. Percec, V.; Popov, A. V.; Ramirez-Castillo, E.; Hinojosa-Falcon, L. A. J Polym Sci, Part A: Polym Chem 2005, 43, 2276-2280.

43. Percec, V.; Ramirez-Castillo, E.; Popov, A. V.; Hinojosa-Falcon, L. A.; Guliashvili, T. J Polym Sci, Part A: Polym Chem 2005, 43, 2178-2184.

44. Percec, V.; Guliashvili, T.; Popov, A. V. J Polym Sci, Part A: Polym Chem 2005, 43, 1948-1954.

45. Percec, V.; Guliashvili, T.; Popov, A. V.; Ramirez-Castillo, E.; Hinojosa-Falcon, L. A. J Polym Sci, Part A: Polym Chem 2005, 43, 1660-1669.

46. Percec, V.; Popov, A. V.; Ramirez-Castillo, E.; Coelho, J. F. J.; Hinojosa-Falcon, L. A. J Polym Sci, Part A: Polym Chem 2005, 43, 779-788.

47. Percec, V.; Popov, A. V.; Ramirez-Castillo, E.; Coelho, J. F. J. J Polym Sci, Part A: Polym Chem 2005, 43, 773-778.

48. Coelho, J. F. J.; Silva, A. M. F. P.; Popov, A. V.; Percec, V.; Abreu, M. V.; Goncalves, P. M. O. F.; Gil, M. H. J Polym Sci, Part A: Polym Chem 2006, 44, 3001-3008. 49. Coelho, J. F. J.; Silva, A. M. F. P.; Popov, A. V.; Percec, V.; Abreu, M. V.; Goncalves, P. M. O. F.; Gi1, M. H. J Polym Sci, Part A: Polym Chem 2006, 44, 2809-2825.

50. Monteiro, M. J.; Guliashvili, T.; Percec, V. J Polym Sci, Part A: Polym Chem 2007, $45,1835-1847$

51. Coelho, J. F. J.; Carvalho, E. Y.; Marques, D. S.; Popov, A. V.; Percec, V.; Goncalves, P. M. F. O.; Gil, M. H. J Polym Sci, Part A: Polym Chem 2007, 46, 421-432.

52. Coelho, J. F. J.; Carvalho, E. Y.; Marques, D. S.; Popov, A. V.; Percec, V.; Gil, M. H. J Polym Sci, Part A: Polym Chem 2008, 46, 6542-6551.

53. Percec, V.; Sienkowska, M. J. J Polym Sci, Part A: Polym Chem 2009, 47, 628-634. 
54. Boyer, C.; Lacroix-Desmazes, P.; Robin, J.-J.; Boutevin, B. Macromolecules 2006, 39, $4044-4053$

55. Goto, A.; Hirai, N.; Wakada, T.; Nagasawa, K.; Tsujii, Y.; Fukuda, T. Macromolecules 2008, 41, 6261-6264.

56. Lansalot, M.; Farcet, C.; Charleux, B.; Vairon, J.-P.; Pirri, R. Macromolecules 1999, $32,7354-7360$.

57. Valade, D.; Boyer, C.; Ameduri, B.; Boutevin, B. Macromolecules 2006, 39, 86398651.

58. Percec, V.; Popov, A. V.; Ramirez-Castillo, E. J Polym Sci, Part A: Polym Chem $2004,43,287-295$.

59. Percec, V.; Popov, A. V.; Ramirez-Castillo, E.; Weichold, O. J Polym Sci, Part A: Polym Chem 2004, 42, 6364-6374.

60. Percec, V.; Popov, A. V.; Ramirez-Castillo, E.; Coelho, J. F. J.; Hinojosa-Falcon, L. A. J Polym Sci, Part A: Polym Chem 2004, 42, 6267-6282.

61. Percec, V.; Ramirez-Castillo, E.; Hinojosa-Falcon, L. A.; Popov, A. V. J Polym Sci, Part A: Polym Chem 2005, 43, 2185-2187.

62. Percec, V.; Guliashvili, T.; Popov, A. V.; Ramirez-Castillo, E.; Coelho, J. F. J.; Hinojosa-Falcon, L. A. J Polym Sci, Part A: Polym Chem 2005, 43, 1649-1659.

63. Percec, V.; Guliashvili, T.; Popov, A. V.; Ramirez-Castillo, E. J Polym Sci, Part A: Polym Chem 2005, 43, 1478-1486.

64. Percec, V.; Popov, A. V. J Polym Sci, Part A: Polym Chem 2005, 43, 1255-1260.

65. Sienkowska, M. J.; Percec, V. J Polym Sci, Part A: Polym Chem 2009, 47, 635-652.

66. Tatemoto, M. Kobunshi Ronbunshu 1992, 49, 765-83.

67. Boyer, C.; Valade, D.; Sauguet, L.; Ameduri, B.; Boutevin, B. Macromolecules 2005, $38,10353-10362$. 
68. Boyer, C.; Valade, D.; Lacroix-Desmazes, P.; Ameduri, B.; Boutevin, B. J Polym Sci, Part A: Polym Chem 2006, 44, 5763-5777.

69. Tatemoto, M. In First Regular Meeting of Soviet-Japanese Fluorine Chemists, Tokyo, Feb, 1979; Tokyo, Feb, 1979.

70. Tatemoto, M.; Tomoda, M.; Ueda, Y. (Assigned to Daikin) Ger. Patent DE 29,401,35 (Chem. Abstr. 1980, 93, 27580). 1980.

71. Hung, M. H. (assigned to DuPont) US Patent 5,231,154. 27.07.1993.

72. Carlson, D. P. (Assigned to Dupont Performance Elastomers) U.S. Patent 5284920. 1994

73. Boyer, C.; Ameduri, B.; Hung, M. (Dupont Performance Elastomer ) U.S. Patent Application 2009/0105435 A1 filed on September 12, 2008.

74. Arcella, V.; Brinati, G.; Albano, M.; Tortelli, V. (Assigned to Ausimont, S.p.A) European Pat. App1. 0,661,312 A1. 05.07.1995.

75. Arcella, V.; Brinati, G.; Albano, M.; Tortelli, V. (Assigned to Ausimont, S.p.A) European Pat. 1995/661312. 1995

76. Gayer, U.; Schuh, T.; Arcella, V.; Albano, M. (Assigned to Ausimont S.p.A) European Pat. 885928. 1998.

77. Boutevin, B.; David, G.; Boyer, C. Adv Polym Sci 2007, 206, 31-135.

78. Perrier, S.; Takolpuckdee, P. J Polym Sci, Part A: Polym Chem 2005, 43, 5347-5393.

79. Monteiro, M. J. J Polym Sci, Part A: Polym Chem 2005, 43, 3189-3204.

80. Goto, A.; Fukuda, T. Prog Polym Sci 2004, 29, 329-385.

81. Fukuda, T. J Polym Sci, Part A: Polym Chem 2004, 42, 4743-4755.

82. Goto, A.; Zushi, H.; Kwak, Y.; Fukuda, T. ACS Symp. Ser. 2006, 944, 595-603.

83. Jaacks, V. Makromol Chem 1972, 161, 161-72.

84. Boyer, C.; Boutevin, G.; Robin, J. J.; Boutevin, B. Polymer 2004, 45, 7863-7876. 
85. Boyer, C.; Boutevin, G.; Robin, J.-J.; Boutevin, B. Macromol Chem Phys 2004, 205, 645-655.

86. Souzy, R.; Boyer, C.; Ameduri, B.; David, G.; Kostov, G. Electrochem Soc Trans $2007,11,15-26$. 


\section{Scheme Caption}

Scheme 1. Radical copolymerization of trifluoromethacrylic acid (TFMA) and vinylidene fluoride (VDF) performed in the presence of 1-iodoperfluorohexane. 


\section{Figure Captions}

Figure 1. ${ }^{19} \mathrm{~F}$ NMR spectra of poly(VDF-co-TFMA) copolymers obtained by iodine transfer polymerization (ITP) initiated by $\mathrm{Na}_{2} \mathrm{~S}_{2} \mathrm{O}_{8}$ at $80{ }^{\circ} \mathrm{C}$ in the presence of $\mathrm{C}_{6} \mathrm{~F}_{13} \mathrm{I}$ (A) (run 2 of Table 1); and $\mathrm{IC}_{4} \mathrm{~F}_{8} \mathrm{I}$ (B) (run 6 of Table 1) as chain transfer agents. (recorded in deuterated DMSO, $400 \mathrm{MHz})$. Note: Copolymerization conditions: $\left[\mathrm{Na}_{2} \mathrm{~S}_{2} \mathrm{O}_{8}\right]_{0} /\left([\mathrm{VDF}]_{0}+[\mathrm{TFMA}]_{0}\right)=1$ mol- $\%$, feed composition VDF/TFMA: 85/15 (mol-\%), $[\mathrm{VDF}]_{0} /[\mathrm{CTA}]_{0}=21.25$ and $[\mathrm{TFMA}]_{0} /[\mathrm{CTA}]_{0}=3.75$.

Figure 2. ${ }^{1} \mathrm{H}$ NMR spectrum of poly(VDF-co-TFMA) copolymers obtained by iodine transfer polymerization initiated by $\mathrm{Na}_{2} \mathrm{~S}_{2} \mathrm{O}_{8}$ at $80{ }^{\circ} \mathrm{C}$ in the presence of $\mathrm{C}_{6} \mathrm{~F}_{13} \mathrm{I}$ as the chain transfer agent (recorded in deuterated DMSO, $400 \mathrm{MHz}$ ) (run 6 of Table 1).

Copolymerization conditions: $\left[\mathrm{Na}_{2} \mathrm{~S}_{2} \mathrm{O}_{8}\right]_{0} /\left([\mathrm{VDF}]_{0}+[\mathrm{TFMA}]_{0}\right)=1 \%$, feed composition VDF/TFMA: $85 / 15(\mathrm{~mol}-\%),[\mathrm{VDF}]_{0} /[\mathrm{CTA}]_{0}=21.25$ and $[\mathrm{TFMA}]_{0} /[\mathrm{CTA}]_{0}=3.75$.

Figure 3. A- Evolution of the functionality in $-\mathrm{CF}_{2} \mathrm{I}$ versus number of VDF units in the copolymer obtained by iodine transfer polymerization of trifluoromethacrylic acid (TFMA) and vinylidene fluoride (VDF) for $\mathrm{IC}_{4} \mathrm{~F}_{8} \mathrm{I}(\boldsymbol{\nabla})$ and $\mathrm{C}_{6} \mathrm{~F}_{13} \mathrm{I}(\boldsymbol{\nabla})$ (feed composition was kept constant, i.e. TFMA/VDF $=15 / 85(\mathrm{~mol}-\%)$; B- Evolution of the functionality in $-\mathrm{CF}_{2} \mathrm{I}$ number of VDF units in the copolymer obtained for the copolymerization of trifluoromethacrylic acid (TFMA) and vinylidene fluoride (VDF) ( $\nabla$ ), for homopolymerization of $\operatorname{VDF}(\bullet)$, and for terpolymerization of VDF, 1,1,2-trifluoro-2pentafluorosulfanylethylene and hexafluoropropene $(\boldsymbol{\Delta})$.

Figure 4. SEC chromatograms in DMF used as the eluent of poly(TFMA-co-VDF) copolymers obtained by Iodine Transfer Polymerization (ITP) for different ratio $\left(\mathrm{R}_{0}=\right.$ $\left.[\mathrm{CTA}]_{0}\right) /\left([\mathrm{VDF}]_{0}+[\mathrm{TFMA}]_{0}\right)$ in the presence of $\mathrm{C}_{6} \mathrm{~F}_{13} \mathrm{I}$ as the chain transfer agent.

Figure 5. Evolution of $\ln \left([\mathrm{VDF}] /[\mathrm{VDF}]_{0}\right)$ versus $\ln \left([\mathrm{TFMA}] /[\mathrm{TFMA}]_{0}\right)$ for the copolymerization of VDF and TFMA. Feed composition in VDF and TFMA 95/5 (mol-\%) in aqueous medium in the presence of $\mathrm{C}_{6} \mathrm{~F}_{13} \mathrm{I}$ as the chain transfer agent. Experimental condition: $\left[\mathrm{Na}_{2} \mathrm{~S}_{2} \mathrm{O}_{8}\right]_{0} /\left([\mathrm{VDF}]_{0}+[\mathrm{TFMA}]_{0}\right)=1(\mathrm{~mol}-\%), \quad[\mathrm{VDF}]_{0} /[\mathrm{CTA}]_{0}=40.0$ and $[\text { TFMA }]_{0} /[\mathrm{CTA}]_{0}=3$. 
Figure 6. Distribution of latex particles of different composition of poly(TFMA-co-VDF)-I copolymers (VDF/TFMA, mol-\%) 98/02, $M_{\mathrm{n}, 19 \mathrm{~F} \mathrm{NMR}}=2800, \mathrm{PDI}=1.85(\boldsymbol{\nabla}) ; 84 / 16, M_{\mathrm{n}, 19 \mathrm{~F}}$ $\mathrm{NMR}=5100, \mathrm{PDI}=1.95(\boldsymbol{\bullet}) ; 90 / 10, M_{\mathrm{n}, 19 \mathrm{~F} \mathrm{NMR}}=3400, \mathrm{PDI}=1.95(\bullet)$. 


\section{Table Captions}

Table 1. Influence of the concentration of CTA on the molecular weights, and polydispersity indices for iodine transfer polymerization (ITP) of VDF and TFMA at $T=80{ }^{\circ} \mathrm{C}$ in water (with or without surfactant). Copolymerization conditions: $\left[\mathrm{Na}_{2} \mathrm{~S}_{2} \mathrm{O}_{8}\right]_{0} /\left([\mathrm{VDF}]_{0}+[\mathrm{TFMA}]_{0}\right)=$ 1 mol-\%, feed composition VDF/TFMA: 85/15 (mol-\%).

Table 2. Poly(VDF-co-TFMA) copolymers carried out by iodine transfer polymerization of VDF and TFMA in the presence of $\mathrm{C}_{6} \mathrm{~F}_{13} \mathrm{I}\left(\mathrm{Ro}=\left[\mathrm{C}_{6} \mathrm{~F}_{13} \mathrm{I}\right]_{0} /\left([\mathrm{VDF}]_{0}+[\mathrm{TFMA}]_{0}\right)=0.02\right)$ at 80 ${ }^{\circ} \mathrm{C}$ (no surfactant used). 


\section{GRAPHICAL ABSTRACT}

Iodine Transfer Copolymerization of Vinylidene Fluoride and $\alpha$ Trifluoromethacrylic acid by Emulsion process without any surfactants

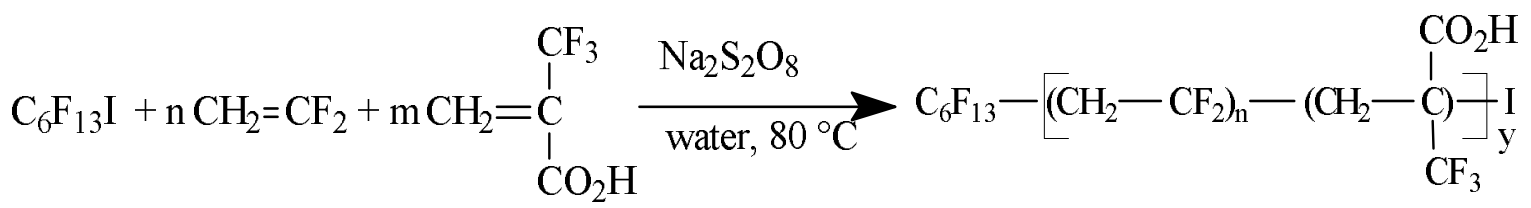

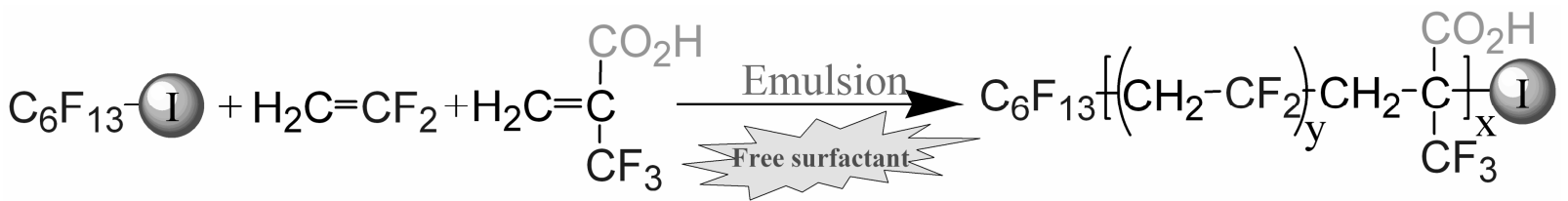

\section{Short Abstract:}

The polymerization of vinylidene fluoride (VDF), hydrophobic monomer, was carried out in emulsion process without addition of surfactant using iodine transfer polymerization. The incorporation of $\alpha$-trifluoromethacrylic acid (TFMA) units in the poly(VDF) by copolymerization allows to improve the stability of these emulsions. 